${ }^{\text {I }}$ Universidade do Estado do Rio de Janeiro (UERJ),

Instituto de Estudos Sociais e Políticos (IESP), Rio de Janeiro, RJ, Brasil

jmdomingues@iesp.uerj.br

José Maurício Domingues'

\title{
TEORIA SOCIAL CRÍTICA E TENDÊNCIAS DE DESENVOLVIMENTO, EMANCIPAÇÃO E COMUNISMO TARDIO'
}

Ao século XIX e à maior parte do XX pertenceram ciências sociais que acreditavam ter em suas mãos a chave do desenvolvimento histórico, da evolução da espécie humana. Isso consistia em herança do Iluminismo, que se traduziu sociologicamente, fosse assim chamado o que faziam os autores que trataram destes problemas ou se referissem à sua produção intelectual de outro modo. Se não, vejamos alguns exemplos muito conhecidos. Embora ainda falasse vez por outra no papel da "Providência", Tocqueville acentuou a marcha da igualdade e da democracia, forças irresistíveis, segundo ele. Marx assinalou o desenvolvimento das forças produtivas e as tendências da acumulação capitalista, bem como a paulatina conscientização da classe trabalhadora de seu papel histórico de coveiro dos sistemas de exploração e de opressão. Durkheim apontou para a crescente divisão do trabalho social e o desenvolvimento da nova "solidariedade orgânica". Weber, ainda que mais cauteloso quanto à direcionalidade do processo histórico em geral e no que tange a determinações unidimensionais, resolveu sua questão ao assinalar, no Ocidente, a racionalização (instrumental) como enteléquia histórica unificadora. O funcionalismo e as teorias da modernização, por um lado, e as diversas leituras do marxismo, por outro, mantiveram vivas essas concepções, amiúde as endurecendo, por vezes suavizando-as. Em suma, tratava-se de tendências de desenvolvimento da modernidade e, por vezes, para além dela, concebidas de maneira mais ou menos determinística, com os conceitos das emergentes ciên- 
cias sociais elaborados em primeiro lugar para dar conta desse tipo de processo (Domingues, 2014).

No entanto, desde os anos I980, com o pós-modernismo, a crise do "socialismo real" e, paradoxalmente, a reafirmação do capitalismo e da democracia liberal, perspectivas que assinalam processos de longo prazo, com lógicas imanentes, internas, caíram em desgraça nas ciências sociais. Para muitos esse resultado era concebido de maneira teleológica, isto é, com fim claro e predefinido, bem como inevitável, além de levar decididamente ao "fim da história". A crise daquelas perspectivas que enfatizavam os processos de desenvolvimento evacuou também o campo do pensamento socialista, que em larga medida nelas se baseara - implicando o desenvolvimento contraditório e autodestrutivo do capitalismo -, não obstante o surgimento de perspectivas de cunho ético neokantiano, como a de Bernstein, à qual voltaremos brevemente adiante. Na verdade, a faticidade do capitalismo e do Estado moderno, burocrático-legal e mais ou menos democrático, garantiu plausibilidade tácita às visões liberais, ao passo que à esquerda o marxismo já não consegue mobilizar argumentos que vão além da descrição de alguns aspectos da realidade, sem ser capaz, para além da retórica, de identificar processos que tendencialmente levem à superação da modernidade.

Afora a apologia pura e simples do presente, duas consequências se fizeram evidentes na teoria social. De um lado, a contingência ganhou centralidade em quase todas as explicações do desenvolvimento histórico, pondo, por exemplo, a "reconstrução do materialismo histórico" de Habermas (I976, I98I), com sua forte teleologia modernista, em posição desconfortável, como um último exemplar talvez das narrativas típicas do século XIX. Nenhuma direção poderia, nas formulações extremas desse tipo de visão, ser, em princípio, assinalada. De outro lado, a política de esquerda se esvai e deslegitima no longo prazo, juntamente com o marxismo, prisioneira das pequenas contingências da realidade imediata, sem projetos de longo prazo (Therborn, 2008), ao passo que outros tentaram fazer da necessidade virtude, retrabalhando de modo pós-marxista, por exemplo, a noção de "hegemonia" de Gramsci em perspectiva fundamentalmente contingente (Laclau \& Mouffe, I989), mesmo se certos discursos filosóficos, sobretudo, ruidosa e superficialmente reivindicam a revolução.

Socialmente, pode-se dizer, de modo sumário, que um duplo processo condiciona a atual situação: à derrota da esquerda somou-se a complexificação social que caracteriza a atual fase da modernidade - e que não é mera invenção do neoliberalismo - e a situação se fez ainda mais confusa e opaca. Assim, por um lado, seja nos espaços do "socialismo real", seja nos países capitalistas, a reestruturação das relações de trabalho, o encolhimento da esfera pública, a alteração nos papéis dos Estados nacionais, o reforço do individualismo utilitarista e a mercantilização de tudo e de todos, sob a égide do neoliberalismo, ca- 
racterizou a ofensiva vitoriosa de uma direita global renovada, o que se fez acompanhar pela perda de capacidade da esquerda para formular alternativas e de certo isolamento social. A isso se superimpôs, por outro lado, a multiplicação de processos produtivos, nichos de mercado, identidades, movimentos sociais, maneiras de ver o mundo, com uma intensificação da globalização e a presença mais forte também dessa esfera global no cotidiano das pessoas, bem como, finalmente, a intensificação dos processos de comunicação. Isso deslocou o debate cultural e político para outros terrenos e aumentou a abrangência das questões que precisam ser respondidas pela esquerda, cujas concepções históricas se mostram estreitas para lidar com muitas dessas novidades, além de sofrer para compreender e enfrentar os já complicados problemas que desde antes se impunham. Enfim, devido a processos de autoisolamento e fechamento do sistema político e estatalização dos partidos políticos, inclusive os de esquerda, em especial os socialdemocratas europeus ou assemelhados em outras paragens, há um hiato crescente entre os desejos de participação democrática e os meios que a possibilitariam, com, em consequência, uma rejeição de crescentes camadas da população à própria política tal qual se configura hoje.

Haveria várias maneiras de enfrentar intelectualmente a reconstrução desses temas e trajetórias mais gerais (ver, por exemplo, para aspectos centrais da discussão, Domingues, I999, 2002, 20I2). Aqui quero, inicialmente, apenas investigar certos aspectos do marxismo nesse sentido - trazendo à luz as principais tendências de desenvolvimento que Marx e Engels identificaram na modernidade, bem como os mecanismos de sua superação, segundo eles, revisitando, ademais, alguns debates centrais dessa corrente de pensamento teórico e político-prático nesse registro. Em seguida, quero indagar sobre as alternativas a essas concepções, que parecem haver se esgotado irremediavelmente, ainda que o marxismo como discurso perdure como central em várias correntes da esquerda, de maneira sistemática ou difusa. Analisarei brevemente duas daquelas alternativas - que são poucas -, presentes de maneiras diametralmente opostas nas obras de Santos e Negri, este há algumas décadas em companhia em especial de Hardt. O marxismo de modo geral não evidencia nenhum avanço teórico significativo recente, ao passo que a teoria crítica de cunho frankfurtiano praticamente se dissolveu, na melhor das hipóteses contentando-se com uma teoria da democracia nos quadros da própria modernidade, sem pretender ultrapassá-la, ou seja, aceitando o capitalismo e o Estado moderno. Enfim, diagnosticando-as como problemáticas para responder aos desafios do presente, tratar-se-á de repor as questões em tela e indagar sobre a possibilidade de articular respostas mais adequadas a elas. Devo sublinhar que destaque aqui é dado à identificação de tendências dentro e para além da modernidade, bem como aos conceitos que nos permitem apreendê-las. Infelizmente, o debate contemporâneo sobre estas questões é extremamente limitado, inclusive, e sobretudo, do ponto de vista das teorias que visam a emancipação. 
Enfatizo ademais que este texto se insere nos quadros do que se pode definir como teoria crítica, em acepção muito mais ampla que aquela que remete à Escola de Frankfurt. Ela inicia-se com a obra de Marx, mas possui hoje caráter ecumênico muito mais amplo, portanto, tampouco restringe-se ao marxismo. Em minha perspectiva, de todo modo - e nas dos autores aqui discutidos, concorde eu com suas conclusões substantivas ou não -, trata-se de buscar nas tendências concretas do desenvolvimento social e nos impulsos emancipatórios que contêm os elementos que podem nos levar a um futuro para além da reprodução de sistemas de dominação e exploração. Em outras palavras, aposta-se em uma crítica imanente da modernidade. Desde Marx e Engels ela se calca na ideia de que a modernidade fez promessas que, em seus quadros institucionais, não se podem cumprir. Em uma visão ampla, ou ecumênica, não necessariamente marxista ou inclusive de corte ocidental, seus sujeitos práticos podem ser vários, desde que sigam, contudo, o critério da liberdade igualitária, valor crucial da modernidade, sem a qual a crítica perde seu rumo e pode acabar conivente com outros sistemas de dominação e exploração. À teoria crítica cabe com dialogar com aqueles agentes, sem permitir-se ser a eles reduzida, mantendo assim sua autonomia, sua própria dinâmica e impulsos internos, para além da experiência dos próprios atores; deve buscar penetrar aspectos da vida social que tendem a escapar à interpretação da experiência cotidiana dos próprios sujeitos que podem ser portadores de projetos de emancipação.

\section{CAPITALISMO, ACUMULAÇÃO E COMUNISMO}

É no Manifesto do Partido Comunista que Marx e Engels (I848) publicizam, com enorme força teórica e retórica, sua visão das tendências da sociedade moderna (à qual explicitamente vinculam o capitalismo). Duas coisas eram claras. Primeiro, tratava-se de uma população proletária - livre civilmente e livre do controle dos meios de produção - expropriada por aqueles que, por seu lado, se tornaram capitalistas. Se entre eles encontrava-se uma pequena burguesia proprietária de seus meios de produção, a tendência de desenvolvimento do capitalismo levava a uma polarização social em que ela desapareceria, subindo ou descendo, com o capital concentrando-se nas mãos de alguns poderosos burgueses e uma constantemente crescendo a massa de trabalhadores (que são sinônimos de proletários na maneira em que articulam o tema) que absorveria os, mais numerosos, decaídos. A produção cada vez mais social entrava ademais em conflito com a apropriação privada da riqueza. Enfim, a organização revolucionária da classe trabalhadora romperia seus grilhões e instalaria o comunismo, projeto político que - observam também em outro escrito (Marx \& Engels, I 845: 38) - acompanhava o "movimento real das coisas" (isto é, a tendência processual da sociedade moderna). A cooperação social generalizada substituiria o caos e a competição do mercado capitalista. 
Não convém exigir precisão demais de Marx e Engels a esta altura, pois estão nos inícios do desenvolvimento de sua obra, embora seus primeiros resultados sejam de porte realmente impressionante. E, não obstante mudanças mais ou menos significativas sofridas por suas ideias, as linhas gerais de seu argumento se manteriam nas décadas seguintes, inclusive no que se refere àqueles que acabaram por ser conhecidos como "marxistas", ainda que o conflito de interpretações cedo se fizesse presente. Em outros textos Marx e Engels se preocuparam com questões eminentemente políticas. Isso teve destaque por ocasião do levante que levou à Comuna de Paris (I87I), com a construção da "ditadura do proletariado", um Estado radicalmente democrático que mediaria a passagem ao "evanescimento" desta própria forma de dominação, a superação do capitalismo e a chegada ao comunismo. O mecanismo de realização desse processo seria em um primeiro momento a subjetividade revolucionária dos trabalhadores, levando ao socialismo como etapa de transição (ainda contando com o trabalho como medida e com os direitos individuais, ainda que cada vez mais igualitários), que desaguaria finalmente em uma sociedade sem classes e sem Estado, porém de economia planificada (Marx, I87I, I875). Estes são temas que posteriormente se tornariam centrais no pensamento marxista.

Seria, porém, em seus textos econômicos que Marx articularia sua visão das tendências de desenvolvimento do "modo de produção" capitalista de modo sistemático, embora também aí com certa dose de ambiguidade. Essas tendências configuraram o que ele definiu como "leis naturais" que orientavam - descontadas variações circunstanciais - os processos e a direção da acumulação capitalista.

No primeiro volume de $O$ capital (1867) Marx tece esses argumentos, que começam com a passagem da "mais-valia absoluta" (vinculada à duração da jornada de trabalho) à "relativa" (em função das lutas defensivas da classe trabalhadora e da própria competição dos capitalistas entre si, a maquinaria e a "subsunção real", direta, do trabalhador ao capital). Adiante assinala vários outros processos. Estes seriam o aumento da "composição técnica" do capital - com mais tecnologia e produtividade -, que implica um aumento de sua "composição orgânica", com aumento do "capital constante" (instrumentos de produção e matérias-primas, sem que nem sempre seja claro se Marx fala disso em termos eminentemente físicos ou de valor-trabalho acumulado, "vampirizado" pelo capital), em detrimento do "capital variável" (a força de trabalho transformada em capital por meio de sua compra). Verificar-se-ia assim um excesso de trabalhadores - uma "superpopulação" relativa - que não pararia de crescer. Ele aponta igualmente para a "concentração" e "centralização" cres centes do capital, destacando percucientemente as tendências à formação de grandes empresas monopolistas no capitalismo avançado, o que implicava sua crescente socialização. A "reprodução ampliada" do capital figurava na base 
dessa crescente acumulação de mais-valia nas mãos de um número cada vez menor ou ao menos associado de capitalistas. Mas, como somente o "capital variável" é capaz de repor o valor investido e criar mais valor, ao exceder as necessidades de sua própria reprodução essa mudança contínua na composição do capital levaria, tendencialmente, a uma "queda" da taxa de lucro, frente à qual se apresentam contratendências, que implicam o barateamento do capital constante, assim como o aumento da taxa de mais-valia, com a questão ao fim e ao cabo simplesmente se desenvolvendo sob a forma de uma espiral, isto é, o problema se repondo em níveis mais altos. Finalmente, expropriados pela "acumulação primitiva" e permanentemente mantidos nessa situação de privação do controle dos meios de produção, os trabalhadores finalmente expropriariam os expropriadores, ponto no qual, ao transplantar a discussão para o plano da ação política revolucionária, Marx interrompe sua argumentação.

Nos volumes seguintes de 0 capital, deixados incompletos e editados por Engels, Marx (1883, I894) retoma vários desses temas. Acrescenta a eles em particular o problema das "metamorfoses do capital", de dinheiro a capital constante e variável, daí a produtos sob a forma de mercadorias que têm de ser vendidas no mercado para que o capital se realize, isto é, retorne, sob a forma dinheiro, com lucro em relação ao que fora investido. Todos os outros elementos que diziam respeito à reprodução ampliada foram retomados. Vale notar também que a questão da polarização social retorna ao centro de suas preocupações. Marx parecia não saber o que fazer com as classes médias - cuja presença é por demais significativa e mesmo crescente para que se sustente o esquema simplificador dos antagonismos de classe que ele e Engels haviam introduzido no Manifesto -, deixando notoriamente inacabado o capítulo que se propôs a escrever sobre as classes. Marx assinalou, porém, conquanto imprecisa e hesitantemente, ao falar das "terceiras pessoas" que se apropriam da mais-valia - para além de capitalistas e trabalhadores, e inclusive dos proprietários de terra -, a importância das classes médias, além do mais como consumidoras, nos quadros desse modo de produção.

Essas são as ideias fundamentais que se pode encontrar em O capital, em termos de tendências histórias de cunho basicamente "infraestrutural" (isto é, econômico), contudo com reflexos diretos nas outras dimensões sociais. Antes de analisar algumas de suas repercussões nos desenvolvimentos do marxismo posteriormente à morte de Marx e Engels, cumpre sublinhar que, se Marx falava abstratamente de "leis naturais" - que pareciam prescindir da subjetividade dos agentes, que seriam, como diz no "Prefácio" ao primeiro volume, meramente persona, suportes do capital em seu funcionamento para além das perturbações contingentes que concretamente poderiam nublar sua identificação -, em outras passagens a questão se coloca de maneira divergente. Afinal, em todas as lutas econômicas entre burguesia e proletariado, não é apenas na esfera imediata da produção, sequer da circulação, mas sim na po- 
lítica e na esfera legislativa, que se jogam os destinos do capitalismo. Obviamente a revolução social passa pela tomada de consciência da classe trabalhadora, mas os capitalistas de modo mais diuturno lutam sempre para manter e ampliar suas taxas de mais-valia e de lucro, incidindo diretamente sobre o plano estatal, mediante leis e violência, para garantir sucesso, como Marx demonstra cabalmente em várias passagens de sua obra-mestra.

Assim, é muito difícil argumentar que seriam apenas aquelas "leis naturais" que subjazem ao processo histórico da acumulação capitalista. Ao contrário, é preciso dividir analítica e concretamente os processos a que se refere Marx em duas categorias. Primeiramente, é, antes de tudo, de uma composição incontrolável e opaca de ações individuais e movimentos coletivos que se deve falar - não de fenômenos efetivamente "naturais", raciocínio com que Marx trai a influência do positivismo sobre suas concepções científicas a esta altura. ${ }^{2}$ Agindo em função de metas mais imediatas, trabalhadores e capitalistas engendram processos tendencialmente orientados - como que presos a uma "dependência de trajetória" impossível de romper - que escapam a seu conhecimento e capacidade de controle, logo, o que se convencionou chamar de “consequências não intencionais da ação". Mas não se deve deixar de notar que, inclusive do ponto de vista da economia, conflitos e regulações que se encetam diretamente no Estado, mais ou menos intencionalmente levados a cabo por indivíduos e subjetividades coletivas (classes e outros agentes, frente ao e dentro do Estado) cumprem papel decisivo no desdobramento das tendências históricas da acumulação capitalista (caso, por exemplo, dos inspetores de fábrica vitorianos famosamente celebrados por Marx).

É mister assinalar também que nos Grundrisse (I857-I858) Marx aponta - de passagem e na verdade em certa medida de modo incongruente - para o papel crescente, diretamente produtivo, da ciência e do "intelecto geral", bem como para o "trabalhador coletivo", cujas emergência e fortalecimento recebem foro de tendência histórica. Isso termina excluído de $O$ capital em parte provavelmente porque daquela forma abriria espaço para identificar o trabalho or ganizador do capitalista como produtor em si de riqueza - o que de certo modo, por outro lado, faz ao retratar, na obra ulterior escrita já para publicação, como ele é fundamental para que o processo de trabalho encontre sua forma propriamente capitalista, com aumento da produtividade e da mais-valia (relativa). Mas mais relevante ainda é que a Max faltava um conceito claro de "trabalho abstrato". Foi este que lhe permitiu retomar sob outra roupagem esses temas nos escritos da década seguinte, como uma larga e consistente discus são vem demonstrando a partir de uma releitura sistemática de sua obra e em particular após a publicação nos anos I980 dos manuscritos preparatórios para os três volumes de 0 capital redigidos nos anos I860-I870 (ver, em especial, Heinrich, 2003, 2013; e, quanto aos Grundrisse, Bellofiore, Starosta \& Thomas, 20I3). Marx pôde assim definir precisamente seus conceitos de "valor" (de uso 
e de troca), mais-valia (absoluta e relativa) e processo de trabalho, de capital constante e variável e de composição orgânica do capital, bem como reformular sua visão das crises (algo até certo ponto oculto na edição de Engels dos volumes 2 e 3 de 0 capital).

Destaque-se a reformulação de sua visão do papel da ciência, que não se opõe, ao contrário, à produção de mais-valia pela força de trabalho, na verdade a impulsiona. A importância daquelas teses preliminares e confusas de Marx de maneira positiva para a obra de Negri se fará manifesta mais adiante, mas não se justifica, deve-se desde já observar, em termos de motivação política e método de abordagem da história do pensamento. Vale notar, em contrapartida, que Marx, conquanto incapaz de teorizar adequadamente a questão do valor, da ciência e os destinos do capitalismo, falava da subsunção do trabalho ao "capital fixo" (maquinaria etc.), embutindo a produção material e espiritual da espécie, pondo-se em oposição ao trabalhador e gerando contradições que somente sob o comunismo seriam resolvidas, de maneira nenhuma já sob o capital, esperando apenas que seu envoltório se rompesse. Esse era o que poderia ser visto como o "núcleo racional" de sua percepção naquele momento. Apenas trabalho seguiria até então gerando valor, ainda que magnificado e com uma potência excessiva ante a estreiteza da capacidade de consumo da sociedade burguesa, o que se resolveria sob o comunismo.

No seio da Segunda Internacional dos Trabalhadores e em particular na poderosa e organizada socialdemocracia alemã, já no século XX, uma infinidade de debates foi encetada (ver Aricó, I976-I977, para um panorama da discussão). O mais notório foi aquele imposto pelo revisionismo de Bernstein (I 899), que negava tanto a inexorabilidade quanto a positividade da revolução, além de pôr em dúvida muitos aspectos da própria teoria de Marx mais geralmente, com a reivindicação do socialismo como projeto de caráter fundamentalmente ético. Da parte dos marxistas - capitaneados pelo ortodoxo Kautsky (por exemplo, I909) - a resposta foi simplesmente reiterar os pontos-chave do que então se definia como marxismo, expressos seja no Manifesto, seja em O capital, seja em outros textos de cunho mais político. Na prática, e a despeito da formação de partidos marxistas à esquerda da socialdemocracia, esta acabou trilhando de fato os caminhos que Bernstein lhe aconselhara, abraçando um reformismo eleitoral e sindical fortemente orientado ao Estado e ao "capitalismo organizado" tal qual articulado inicialmente por Hilferding, em que a própria ideia de socialismo, para não falar de comunismo, acabou por desaparecer. A questão do imperialismo, tal qual formulada, de maneiras diversas, especialmente por Luxemburg e Lênin, com a mobilização pela primeira dos esquemas da "reprodução" - "simples" e "ampliada" - de Marx, de uma maneira que lhe granjeou fortes críticas foi outro ponto de polêmica. No que diz respeito ao tema que busco tratar aqui, ou seja, a ideia de tendências no desenvolvimento do capitalismo e da modernidade, é interessante apontar para o debate sobre seu (in)evitável "colapso". 
A disputa tinha como foco as teses de Marx sobre o aumento da composição orgânica do capital e a lei da tendência à queda da taxa de lucro (ver Sweezy, I946). Luxemburg (I9I3) defendia a tese de que, bloqueada a possibilidade dos lucros se manterem em níveis necessários, o colapso do capitalismo seria inevitável. Ademais, era preciso sustentar esse determinismo, do contrário a própria viabilidade do movimento socialista seria ameaçada, pois teria, pode-se dizer, de lidar com a contingência, se essa "lei" ficasse aquém de uma tendência que no longo prazo levaria a impasses insuperáveis nos limites daquele modo de produção, minando-se assim a confiança e o entusiasmo dos militantes revolucionários. Outros, especialmente Grossmann (I929), criticaram a forma com que Luxemburg articulou seus argumentos, mas rechaçaram as perspectivas de seus críticos, como Bauer, reafirmando a inevitabilidade do colapso do capitalismo, ao passo que Kautsky oscilou entre as duas posições (possivelmente por haver conhecido os textos originais preparatórios de Marx para os volumes 2 e 3 de 0 capital, em que o tema era tratado de forma bem mais suave que aquela em que terminaram publicados por Engels - como assinalado por Heinrich, 20I3). Que papel teria a subjetividade coletiva revolucionária da classe trabalhadora frente a isso é tema que ficava pendente nessa discussão. Lênin ele mesmo parece não ter nunca aceito a validade da perspectiva catastrofista, acentuando a necessidade, por outro lado, de um partido revolucionário para operar a derrubada do capitalismo, ainda que concentração e centralização do capital, bem como sua exportação e a colonização da periferia pelos Estados europeus estivessem nos fundamentos do imperialismo e da crise geral do sistema (Lênin, I9I7). O debate marxista se desdobrou de forma sistemática ao menos até os anos 1950 com posições variáveis, reverberações menores ecoando até nossos dias.

Hoje muitos desses debates parecem pertencer a um passado muito longínquo, a um mundo que nada tem a ver com o nosso, no qual se falava de revoluções e leis do desenvolvimento social, dois temas no mínimo problemáticos contemporaneamente, tempo de reformismo inclusive muito mais fraco que qualquer coisa que a socialdemocracia alemã pudesse sugerir naquele momento histórico e de suposta acentuação, hoje, da contingencia do desenvolvimento social. Embora, como mencionei anteriormente, uma releitura da economia política de Marx tenha se realizado nas últimas décadas (ver Heinrich 20I3, por exemplo), poucos são os que se mantêm na linha de argumento da economia política marxista.

Esse é, porém, notadamente o caso de Harvey $(2003,2009)$. Isso inclui seu conceito original de "acumulação por despossessão", sua retomada também do conceito de imperialismo e ênfase na expropriação dos bolsões não capitalistas contemporâneos, estatais, pré-capitalistas etc. Em contrapartida, nada ou quase nada daqueles debates sobre o colapso do capitalismo, muito menos tese semelhante, se encontra em suas obras (embora Harvey, I990, re- 
colha de Luxemburg a ideia de necessária expansão geográfica do capital para superar suas crises). O diagnóstico do presente permanece nos quadros do marxismo tradicional, mas quando se chega à construção de alternativas o que Harvey (20I4) destaca é uma perspectiva lefebvriana restringida, apontando a vida cotidiana como a esfera decisiva da luta contra o capitalismo (diferentemente do próprio Lefebvre, vale assinalar, que a via como aspecto complementar estrategicamente). E por aí ficamos, salvo por proclamações vagas a respeito da inevitabilidade da revolução socialista. É verdade que se pode argumentar que a expansão global do capitalismo reporá mais adiante exatamente os problemas que o marxismo do começo do século enfatizou. Essa literatura poderia inclusive renascer e servir de fonte de inspiração para o futuro, quando finalmente todo o mundo estiver subsumido ao capital realmente, sem sequer espaço para a "acumulação por despossessão", destacada por Harvey como forma de valorização do capital global financeirizado de nossos tempos. É ideia plausível, mas no fundo incorreta, pois não leva em conta a mudança de muitos aspectos da realidade social, que, mesmo se aqueles fatores continuam em operação, é bastante distinta daquela que Marx e Engels, Bernstein e Kautsky, Luxemburg e Lênin conheceram e teorizaram.

\section{ALTERNATIVAS CONTEMPORÂNEAS}

Vale examinar agora sumariamente duas alternativas contemporâneas dentro do campo da teoria crítica, com visões bastante distintas. Ambas identificam tendências de desenvolvimento que operariam fortemente hoje, mas de caráter inteiramente distinto e com consequências políticas também com direções divergentes. Não viso aqui esmiuçar suas teorias, esforço que se justifica em ambos os casos, senão delinear algumas questões básicas em termos das alternativas processuais e teleológicas que se pode esperar de uma abertura emancipatória da modernidade. Conforme observado na introdução e na seção anterior, afora repetições rituais e pequenos avanços, o marxismo enquanto tal não deteve, nas últimas décadas, nesse aspecto da teoria e os neo ou pós-frankfurtianos já não se preocupam com essa temática.

Boaventura de Sousa Santos possui uma obra que evoluiu sistematicamente ao longo do tempo, mas alguns elementos fundamentais se podem destacar em seus escritos (basicamente aqui aventados através de Santos, I995, I999, 2000, 2007). Se começou com uma perspectiva em que se destacava, em uma veia pós-modernista, a crítica ao racionalismo ocidental, aos poucos sua visão foi se expandindo. Identificou, desde há muito, uma "transição paradigmática", sobretudo epistemológica - esta a verdadeira tendência operante hoje, a qual engloba inclusive a teoria crítica, levando-nos para além de Marx. Ele a enquadrou inicialmente pelo pós-modernismo e, enfim, crescentemente e com ele combinado, o pós-colonialismo. Assim, é o caráter homogeneizador 
e orientado fortemente ao futuro da modernidade que ele irá recusar, incluindo o Estado moderno, cujo projeto se assentaria na ideia de uma nação una, homogênea e exclusiva. Os espaços de experiência contemporâneos - versus a orientação futurista da teoria crítica até hoje -, argumenta, devem ser valorizados, recusando-se o desperdício daquela, particularmente no plano da epistemologia, em oposição à razão ocidental, cientificizada. O mesmo vale para o pluralismo social, e o direito, sobretudo com a rejeição das soluções ocidentais, que está na ordem do dia, segundo ele, bem como uma nova utopia realista que enalteça e promova essas alternativas. É para aí que rolam as águas, é nessa direção que ele quer apostar, de forma a ultrapassar os impasses e os excessos de regulação, sobretudo estatal, e da secundarização da comunidade realizados no Ocidente desde o surgimento da modernidade, afirmando ainda a necessidade de ampliação da democracia e a abertura à experimentação social, inclusive em escala circunscrita.

Buscando um substituto para o proletariado marxista, Santos retoma o pluralismo da teoria dos movimentos sociais dos anos I980, radicalizando-o e trazendo, enfim, para o centro de suas afirmações a ideia de que o "Sul global" - rompendo com sua própria crosta interna imperial - pode ter papel privilegiado a cumprir na "transição paradigmática" que se encontra em curso. Por exemplo, a Constituição e o Estado plurinacionais da Bolívia e do Equador, "desde baixo" invertendo a lógica do constitucionalismo, historicamente de caráter liberal, seriam ao menos em parte expressão do pós-modernismo e da descolonização, ainda em processo de transição de longo prazo (que incluiria, sugere, o declínio, ou algo parecido, do capitalismo). De todo modo, Santos interessantemente observa que o Estado é ele mesmo um campo de lutas e assim deve ser disputado pelos movimentos populares, impulsionado em uma direção democrática inclusiva e experimental.

Criticamente, pode-se sugerir que o problema principal de suas teses é que o diagnóstico dos processos sociais contemporâneos acaba subordinado a uma visão demasiado geral - além de, nesse sentido, apriorística e, a exemplo de Weber, unificada por uma concepção de racionalização redutiva. Ao mesmo tempo os processos propriamente sociais que subjazem à sua produção recebem tratamento secundário. Em particular, Santos se esquece de tema que em Marx e Engels seria fundamental, qual seja, a definição da teoria crítica como emancipadora não apenas genericamente, mas por ser capaz de apontar os caminhos da realização, fora da modernidade, dos valores que ela mesma prometera concretizar, sem que suas instituições o permitam. Além do mais, ele perde de vista como o pluralismo - assim como foi o caso de esforços homogeneizadores emancipatórios no passado - pode não desafiar ou sequer incomodar os sistemas contemporâneos de dominação, os quais na verdade já aprenderam muito bem a lidar com esse tipo de desenvolvimento social, assim como souberam lidar com os projetos de emancipação calcados na homoge- 
neização, seja da cidadania ou da classe operária como sujeito universal. Acaba, portanto, reificando a diferença, sem indagar acerca de seu significado contextual, pois não deve ser vista nunca como positivamente absoluta; e mesmo quando o é.

Mais ainda, as novas epistemologias a que se refere nunca são apresentadas concretamente. "Ecologia dos saberes" e "tradução intercultural" seriam especificamente os instrumentos das epistemologias do Sul, argumenta Santos (20I0: I08-I09). Mas que se trata aqui efetivamente de operações do conhecimento não é nada claro, para não falar da caricatura que é traçada das ciências sociais modernas. Tampouco se entende por que mera plurinacionalidade (com sua pluralidade) nos levaria para além do Ocidente e da modernidade (existindo, por exemplo, há décadas na Índia, sem em nada desmentir seu caráter nacional moderno e a modernização em geral desse enorme país asiático). Trata-se de argumentos exagerados e de pouco auxílio para sair dos impasses atuais. Enfim, que haja excessos e impasses da regulação não implica que uma transição paradigmática se apresente, suponha-se ou não que ela é a solução dos problemas. De todo modo, seu lema - "um conhecimento prudente para uma vida decente" - tem a virtude de atribuir uma posição mais modesta à razão e às teorias sobre o presente e o futuro (se bem que sua visão tão abrangente ponha em dúvida se aplica a máxima a si mesmo, problema mais geral do pós-modernismo), assim como se destaca a ênfase, a bem da verdade hoje um consenso ao menos retórico, na demanda de aprofundamento da democracia e, em especial, na experimentação social.

Antonio Negri, por sua vez, claramente assinala, em várias ocasiões, de maneira direta ao prefaciar uma segunda edição de uma de suas obras em que pela primeira vez apresenta uma visão sistemática do novo "trabalhador social" e retomando o cerne de seus argumentos nela mesma e em outras ocasiões, que os textos de Marx são todos eles articulados pela identificação de "tendências" de desenvolvimento da modernidade (Negri, 2005: Io). É exatamente o que ele quer reiterar e, nesse sentido, sua relação com o marxismo é bastante estreita e na verdade tributária de uma visão de mundo que a muitos aprazaria relegar ao século XIX e ao trágico XX, não obstante a influência crescente de Nietzsche e dos nietzschianos franceses sobre sua concepção totalizante da vida social e de sua transformação. A rigor, Negri vai mais longe que Marx e radicaliza a abordagem das tendências, tratando enorme quantidade de temas em um enquadramento deste tipo, mesmo quando em Marx isso não se põe ou tal ocorre apenas parcialmente. ${ }^{3}$

O argumento de Negri está calcado na tese da passagem do trabalhador "massa" ao trabalhador "social", por volta dos anos I970 no Ocidente. Aquele era típico do fordismo desqualificador, este é produtor de comunicação, cultura e afetos, com forte peso da ciência. Esta sua leitura busca mobilizar, como já assinalado, os Grundrisse, enfatizando o papel da subjetividade de maneira 
imediata, ao propor uma leitura ingênua e reducionista de Marx, curiosa se não fosse motivada politicamente ela também de forma imediata e não geras se inevitavelmente graves distorções, que serão examinadas adiante (Negri, I979, 2005; ver, também, Hardt \& Negri, I994). Como fruto das lutas de classe (sem que ele dê qualquer importância à concorrência entre os capitalistas), nesse novo quadro o capitalismo alcançaria a "subsunção real" da totalidade social e se apropriaria de um valor em larga medida "imaterial", que por fim Negri definiria como "biopolítico", gerado de maneira genérica na sociedade, não mais apenas na fábrica ou pelo trabalho estrito senso. Além disso, já não haveria "sociedade civil" que desse sustento a um projeto reformista. ${ }^{4} \mathrm{O}$ Império desterritorializado que emergiu na virada do milênio generalizaria essa forma (mais recentemente reconhecendo eles o papel dos Estados nacionais, posta a insustentabilidade daquela tese, que se torna incongruente).

Negri muda de posição nas margens de sua proposta para tentar inclusive lidar implicitamente com as objeções de seus críticos, mas um tema central perdura em seu pensamento: a organização do proletariado (e de seus diversos sinônimos ao longo de sua obra: "multidão", como sua expressão política, e, finalmente, "pobres") se calca de forma imediata em sua "composição social" (no que revisita e transforma a discussão marxista já acima analisada). Ele recusa veementemente autonomia à política (e a divisão do trabalho que a acompanha), posição que vem desde os inícios de seu embate com o Partido Comunista Italiano. Por outro lado, simplesmente descartou o socialismo como fase de transição ao comunismo. Este estaria imediatamente disponível e deveria ser realizado de forma absoluta e imediata, contra, obviamente, a perspectiva do próprio Marx. O Estado enquanto tal, há décadas já convertido em mero agente do capital, é um inimigo com o qual não poderia haver conciliação. Sobretudo o processo de trabalho seria, segundo Negri, fundamentalmente independente do capital a esta altura - este e o próprio Império seriam meros "parasitas". Não somente se nutrem das energias do trabalhador e da multidão, mas em nada contribuem para a organização da própria produção, ao contrário do que ocorria em períodos anteriores. Com isso o comunismo é já uma realidade que espera apenas descartar a crosta inútil e corruptora das forças dominantes (com, ao menos em Império, a defesa pura e simples de um "êxodo" das instituições, encarnado àquela altura pelos imigrantes globais). A multidão, conceito difícil e bastante difuso, é uma mescla mais uma vez direta entre singularidades - monadológicas, irrredutíveis - e generalidade, conformando uma totalidade absoluta, sem que intervenham em sua composição coletividades intermediárias (o que não chega a ser dito explicitamente, mas encontra-se implícito). Ela seria o agente dessa transição sem paradas intermediárias.

Se alguns desses elementos não se acham ainda plenamente desenvolvidos, e não está claro em suas obras quais estão e quais não, o que importa 
para Negri - e Michael Hardt, seu principal colaborador desde a década de I990 - é precisamente assinalar quais tendências comandam o desenvolvimento da modernidade e sua superação. Isso se faria hoje através da reapropriação do "comum" (the commons), na qual intervém, ainda que de maneira restrita - sempre com a recusa de qualquer esquema de representação política - alguma espécie de mediação dentro da multidão. Nesse processo revolucionário algumas das características que constituem grupos particulares (que se vinculam às críticas que Hardt e Negri receberam, mas também por vezes com modas acadêmicas), como mulheres, raças e colonizados, são assinalados, mas dissolvidos, através de uma política de "liberação" que vai além de sua mera afirmação emancipatória, porém conservadoramente congelante.

Santos evidencia os problemas da fragmentação social elevada à solução dos problemas que o bloqueio da superação socialista da modernidade engendrou ao longo do século XX. Negri, ao contrário, se mostra herdeiro direto da Terceira Internacional e de sua visão totalizante. Mais curiosamente, desdobra um determinismo econômico e sociológico brutal ao derivar da "composição social" da classe trabalhadora sua realização política, embora, ciente das críticas que por isso lhe foram endereçadas, tente rechaçar, sem nenhum argumento de fato, essa caracterização (Hardt \& Negri, 20 I I: 354). Se esta é operação bastante estranha (ao juntar economicismo a uma teoria do valor totalizante, genérica e fundamentalmente equivocada, com uma leitura bastante forçada dos Grundrisse, que, como já assinalado, desconhece ademais seus limites e desenvolvimentos posteriores da obra de Marx), ainda mais problemática e de consequências políticas potencialmente deletérias é a série de equivalentes retóricos entre proletariado, multidão e, finalmente, "pobres", cuja constituição é exclusivamente positiva, contraposta ao parasitismo e à corrupção em que se baseiam capital e Império. A isso se somam, piorando as coisas, a falta de mediações políticas e de particularizações no que tange às subjetividades coletivas que tecem os possíveis projetos de emancipação. Não importa aqui realmente seguir em detalhe seu envolvimento na política da ultra esquerda italiana nos anos I970-I980 - não obstante as limitações burocráticas e reformistas do PCI àquela altura -, o que de resto Negri (I998, por exemplo) veio ao menos em parte a reconhecer posteriormente, problema que se repõe em situações semelhantes. Cumpre apenas enfatizar que sua concepção de uma totalidade espontânea e sem mediações não pode senão convocar o desastre nas filas da esquerda, apesar de seu distanciamento em relação à violência ofensiva e da introdução de um mínimo de mediação em sua obra recente, no que tange à (re)construção do comum (Hardt \& Negri, 20 I I: 353ss). Nesse sentido, não obstante seu flerte com o nietzscheanismo francês, o peso de uma versão que radicaliza a ontologia marxiana é excessivo e a rigor ultrapassado, enquanto sua simplista oposição entre poder constituinte e constituído, ou biopolítica e biopoder (Negri, I992), supostamente a partir de Spino- 
za e de Foucault, reproduz na verdade lugares já bastante comuns do pensamento ocidental, radicalizados unilateralmente no poder constituinte ou no êxodo.

Muito seria necessário fazer para poder dar conta, em maiores detalhes, da obra de Santos e Negri. Essas consistem, de todo modo, nas linhas mestras de seu pensamento. Acima de tudo, servem-nos para pôr em tela de juízo os elementos fundamentais aos quais uma teoria social crítica, transformadora, aberta ao século XXI, tem de responder.

\section{TAREFAS DE UMA TEORIA CRÍTICA-OU O COMUNISMO TARDIO DO SÉCULO XXI}

Por muitas décadas o marxismo foi a teoria quase inconteste de todos os movimentos anticapitalistas no mundo, ainda que várias fossem as leituras a que se prestou. Hoje, é patentemente insuficiente, embora não se deva subestimar o quanto ainda é capaz de servir a um diagnóstico de muitos aspectos da realidade do capitalismo. Se isso é verdade, não há como salvar traços centrais de sua constituição como teoria social. O primeiro é relativo à própria definição do materialismo histórico, para o qual a economia e os interesses daí derivados são o ponto de partida causal e, portanto, analítico da vida social e de sua compreensão. Não quero elaborar esse tema aqui, pois há um largo debate, em especial na sociologia, que põe interrogações e oferece soluções, mais ou menos adequadas, para essa questão. No contexto deste artigo, se se deve dizer que em Marx o problema é complicado, piores são suas reverberações em Negri, com sua identificação entre trabalhador social e comunismo em estado prático, com a recusa absoluta em aceitar uma dinâmica das práticas políticas em que certo grau de autonomia tem de ser reconhecido, inclusive com a formação de identidades que se referem diretamente a elas. Por outro lado, Marx acentuava o papel de subjetividades coletivas que medeiam entre o geral e o singular, o que a ideia de multidão de Negri totalmente descarta, com ademais a radicalização de uma concepção da vida social em que a subjetividade (não é claro se centrada ou descentrada, intencional ou não) adquire absoluta preeminência.

Sobretudo em uma formação social ou civilização em que se verifica crescente complexificação - de identidades, esferas, práticas -, isso precisa ser reconhecido. É disso que tratavam Laclau e Mouffe (I989) antes de principalmente aquele deslizar para uma apologia simplificadora do "populismo" (Laclau, 2007; ver, também, Domingues, 20I3) como instância absoluta de unificação das subjetividades populares, algo raro e improvável nas condições contemporâneas, o que de resto só pode ocorrer mediante a "articulação" que eles mesmos discutiram em relação à categoria, transformada, de hegemonia em Gramsci. Por outro lado, é justo aí que residem as virtudes e mistificações 
da obra de Sousa Santos, ao afirmar e fazer uma apologia excessiva, em nome em parte de uma pluralidade epistemológica, de uma multiplicação de subjetividades coletivas particulares, sem que ofereça critérios em torno aos quais pode e deve se compor em um projeto emancipatório, bem como, a esta altura, com pouca análise sociológica daquilo sobre o que se assentam, logo as naturalizando.

Em outras palavras, trata-se de reconhecer a pluralização crescente da vida social e a necessidade de criar mediações emancipatórias (ou liberatórias, se se quer distinguir aquilo que na realidade se apresenta indistintamente), produzir alianças a partir de temas concretos e impulsionar a democracia a partir de sua dimensão política, o que não quer dizer que se deva perder de vista a dimensão social imediata nem a transformação radical da sociedade moderna, para além dela própria. Mesmo aqui há dificuldades, pois a visão marxista do comunismo, ou seu sucedâneo em Negri, o "comum", não se dá de forma imediata em uma suposta dispensabilidade do organizador e de certa hierarquia. Esta é inevitável, como sabemos, em organizações, que nunca se articulam de maneira simplesmente em rede, ou "rizomática", o que gera um problema permanente de instituição, controle e desinstituição democráticas de modo a superar os impasses da "lei de ferro da oligarquia" segundo Michels (I9I5). O problema é dramático, mas não há passe de mágica que o faça desaparecer, como espera Negri, inclusive na inevitabilidade da representação em uma formação social global altamente complexa como a nossa. Claro, problema ainda mais espinhoso se põe no que tange às grandes corporações, a base do que seria, via socialização dos monopólios, a própria construção do socialismo, rumo ao comunismo, de acordo exatamente com as leis tendenciais da acumulação capitalista. É difícil confiar, por problemas burocráticos e raio de ação, no Estado nacional para fazê-lo, sem falar das bases de apoio e mobilização popular que seriam necessárias para operar tal política, sem falar do enorme alcance das corporações transnacionais. Mas ela não pode deixar de estar em questão, por outro lado, se não nos contentamos com pequenos passos na vida cotidiana, como sugere Harvey, nem com a reivindicação de cidadania que, surpreendentemente, se põe nas propostas ou demandas práticas dos escritos publicados no novo milênio por Hardt e Negri (200I, 2004, 20I I).

Em certo sentido, é prioritário identificar exatamente em que aspectos dos sistemas políticos se deveria intervir para romper com o que parece ser a lógica inexorável e insuperável da democracia liberal como guardiã do capitalismo, e em parte de outras formas de opressão social. O que chamei em outros contextos de liberdade igualitária - ou seja, a distribuição igualitária do poder entre agentes capazes de intervenção sobre sua vida e na dimensão coletiva - é valor e telos que deve orientar essa perspectiva. Esse é critério que de resto falta a Santos, no máximo estando implícito e seja modernamente contrabandeado para dentro de seus argumentos sobre a emancipação, ainda que na obra 
de Negri ele se apresente de uma forma ou de outra também implícita, porém mais positivamente. Mas em si isso não nos diz como efetivar essas aberturas da democracia, nem o que poderia colocar-se mais além desse passo, por exemplo e em especial, no que tange às grandes empresas capitalistas, que de forma alguma são simplesmente parasitárias no que tange à produção, afirmação forte, mas não corroborada empiricamente na análise - ou mera postulação - de Negri, o que em parte funda sua visão ultra esquerdista e revolucionarista há tempos, ao transbordá-la para o plano político. Não podemos simplesmente inventar o que seriam essas transformações, mas é preciso ao menos buscar na realidade atual as tendências - em especial na política como sistema relativamente autônomo da modernidade, ainda que apareça como uma reificação que define em larga medida a divisão do poder social em relação sobretudo ao Estado. Pouco se faz hoje nessa direção, afora os esforços, a meu ver limitados ou problemáticos, dos autores aqui mencionados diretamente, embora em plano mais genérico e mais atinente à teoria política outros exemplos disso possam ser apontados na tradição crítica, em sua derivação, de bom ou de mau grado, para as vizinhanças do liberalismo (ver Habermas, I992; Cohen \& Arato, I992; Kalivas, 2005).

Que há uma inevitável, goste-se ou não, dialética entre instituinte e instituído, sabemos ao menos desde Marx e suas "Teses sobre Feuerbach" (I845), o que Sartre (I960), entre outros, nos reafirmou também, acentuando, vale observar, as construções e mediações coletivas, ainda que visando excessivamente à totalização dialética da história. De resto, isso é algo que Negri não desconhece. Obviamente, essa dialética engendra os problemas que cristalizações de poder autonomizadas implicam para a construção da democracia, sem que haja soluções mágicas para eles, mesmo em processos de transformação radical. O que cumpre considerar são quais rumos esta toma hoje e que pontos devem ser tensionados para empurrá-la na direção de sua dimensão instituinte (ou, pouco importa a palavra, "constituinte", desde que não homogeneizada, monadologizada e/ou absolutizada). Isso se aplica aos sistemas políticos de modo geral, bem como às organizações populares, além do mais sem que saibamos como construir sistemas de mediação que não destruam aquilo que é mediado. Aqueles sistemas têm de fato certo grau de autonomia em relação a outros sistemas sociais, e assim devem ser tratados, a saber, como sistema de mediações em sociedades complexas, o que não quer dizer que se deva promover sua independência em relação às lutas e à criatividade populares, nem que em outro tipo de civilização permaneceríamos com o mesmo desenho institucional.

Trata-se, do ponto de vista de uma renovação da teoria crítica, de uma agenda de pesquisa indispensável nos dias de hoje, no centro da qual república e afirmação das massas, inclusive em sua autonomia (o que hoje se expressa em formas várias e insuficientes de neoanarquismo explícito e declarado, 
por vezes como inspiração mais difusa), não pode figurar senão com centralidade. ${ }^{5}$ Nesse sentido, se o espaço global se afirma cada vez mais como esfera necessária da emancipação, os Estados nacionais seguem sendo o recorte mais acessível e imediatamente produtivo das lutas sociais, insubstituível por ora, embora ligações por sobre suas fronteiras sejam também crescentemente importantes. Igualmente imprescindível é voltar a dar ênfase na questão do capitalismo, acima de tudo no que tange às grandes corporações. E cumpre, é claro, mais uma vez retomar a discussão sobre as subjetividades coletivas transformadoras, não, porém, aquelas postas por qualquer filosofia genérica, senão as que se podem localizar empiricamente, em suas tendências concretas de desenvolvimento, assim como Marx o supunha em O capital e hoje nos conformamos com perder de vista. Se não cabe permanecer nas margens derridianas, tampouco é o caso de radicalizar a dialética negativa de Adorno ou simplesmente abraçar a filosofia deleuziana da diferença. A crise da metafísica já há tempos, começando com Marx, nos indicou o esgotamento da filosofia em sentido clássico. Somente a análise científica dos fenômenos sociais pode efetivamente nos orientar, ainda que ela deva, a seu modo, incorporar a responder às grandes questões da tradição filosófica, sem a ela sucumbir.

A derrota do socialismo, tal qual configurado no "socialismo real", mas não apenas nele, impõe a revisão de todas as expectativas dessa tradição, sem render-se a seu abandono. O comunismo - mais que o capitalismo, na versão frankfurtiana - é um projeto tardio na modernidade hodierna, no sentido de que tarda e talvez tenha atingido um climatério frustrado. Nada nos diz, afora proclamações otimistas sem sustentação de modo algum inequívoca na realidade, ao estilo do que Luxemburg enfatizava, que sua hora chegará. Se queremos realizar, contudo, a liberdade igualitária que a modernidade nos prometeu e não pode ela mesma realizar, em virtude dos sistemas de dominação que a atravessam e constituem, devemos abraçar a contingência de sua possível realização e buscar as tendências de desenvolvimento que nos poderiam sugerir caminhos mediante os quais seja superada. Elas de forma alguma configuram "leis naturais", sequer na economia, menos ainda na política, embora esta tampouco esteja sujeita realmente à totalidade dos desígnios dos agentes que a tecem. Assim, se a emancipação social e humana será algum dia efetivada, depende ela de nossa vontade, expressa hoje, ainda que limitadamente, em um amplo espectro de contestações sociais que não reproduzem mais simplesmente a época áurea do movimento operário revolucionário, embora tenha levado, como sabemos, muito tempo para que o desejo de voar da espécie humana tenha podido se concretizar, de formas não imaginadas e inimagináveis durante quase todo o curso de sua evolução, como Brecht e outros assinalaram. Em sua pluralidade e possível convergência, precisa ser impulsionada e perseguir caminhos mais radicais para continuar avançando ao menos como tendência que pode se desdobrar rumo ao futuro. Para isso pode servir a teoria social cientificamente informada. 
É preciso nesse sentido um pouco de modéstia. Já não há lugar de fato para formulações que se assemelhem a cosmologias totalizantes, nem delas carecemos, ainda mais se derivam de um princípio simples, quase emanacionista. É discutível mesmo se Marx abraçava algo dessa natureza, apesar de seu compromisso com a ideia de totalidade e seu unilateralismo histórico de cunho econômico, quaisquer que sejam as qualificações que a ele se possa aduzir. De todo modo importa à política mover-se impulsionada pelos sujeitos sociais - os quais necessitam, a meu ver, de uma teorização mais avançada, como a que tentei com conceitos como o de sua subjetividade coletiva, incluindo consequências não intencionais, e criatividade social -, conquanto a teoria seja força ela também efetiva ao mesclar-se com as práticas sociais e ajudar a organizá-las, dialogando com a multiplicidade de coletividades que de uma forma ou de outra portam projetos de emancipação social. Convém que isso se realize hoje com a teoria se pondo de maneira mais circunscrita, empírica e científica, assim como com a manutenção de sua autonomia. Isso pode produzir, com efeito, um conhecimento ousado e incisivo, com critérios emancipatórios claros, porém, aí sim, mais prudente, como quer Santos, sem por outro lado perder-se no empiricismo e no localismo, sem compromissos ademais com a pluralidade por si mesma.

Nesse sentido avançar-se-ia com o espírito de Marx, ainda que sem incorporar inteiramente seu compromisso demasiado forte com uma visão da totalidade, que não deve ser, no entanto, dentro de certos limites e consideradas as mediações da prática científica, descartado. Este segue sendo um desafio da teoria crítica: trazer à luz as tendências que apontam para o futuro, pensar como explorá-las na direção da emancipação e buscar a totalidade, sim, mas sem supor que a alcançou jamais, portanto precavendo-se de projetar cenários demasiado abrangentes e a priori para a mudança social. A política transformadora prescinde e deve recusar qualquer coisa a mais do que isso.

Recebido em 07/06/20I5 | Aprovado em 03/II/20I5

José Maurício Domingues é doutor em Sociologia pela London School of Economics and Political Science (LSE) e professor e pesquisador no Instituto de Estudos Sociais e Políticos da Universidade do Estado do Rio de Janeiro (IESP-UERJ). Entre seus últimos livros encontram-se Teoria crítica e (semi)periferia (20I I), Modernidade global e civilização contemporânea. Para uma renovação da teoria crítica (2013), O Brasil entre o presente e o futuro. Conjuntura interna e inserção internacional (2a. ed. revista e ampliada, 20I5) e, como coeditor, Global modernity and social contestation (2015). 


\section{NOTAS}

I Agradeço a María Elena Rodríguez os comentários à versão anterior deste texto e a Cunca Bocayuva Cunha por discussão sobre as obras em tela.

2 Por outro lado, a recorrente ideia, em O capital e alhures (nos próprios Grundrisse, em especial), de que é preciso ir além da "aparência", rumo à "essência", ou abstrair dos processos concretos que perturbam o curso normal das leis sociais-naturais, contrapondo-se necessidade e contingência, corresponde a elementos de metafísica que perduram sem elaboração adequada no pensamento de Marx, inclusive com analogias inadequadas com o estudo dos astros. No primeiro caso trata-se de reconstruir o argumento mediante uma versão de realismo analítico, preponderante inclusive no pensamento do próprio Marx; no segundo, de não separar processos e contingência da regularidade de certas práticas sociais - em seus aspectos intencionais, bem como não premeditados -, de modo a mais adequadamente construir os "conceitos-tendência" capazes de captar as direções de surgimento, reiteração e superação das relações sociais. Elster (1985, passim) deu adequada atenção à questão das consequências não intencionais (ainda que nos quadros de um equivocado "individualismo metodológico"), mas não as relacionou às "leis naturais", nem à queda da taxa de lucro, com ademais um estranho argumento quanto ao tema da essência e aparência.

3 Ver Murphy (20I2) para uma discussão geral da obra de Negri e de sua trajetória política. Observe-se que temas como o "operário social" eram bastante generalizados no "obreirismo" italiano dos anos I960-I970; como em Mario Tronti, particularmente, que chega a conclusões opostas às de Negri quanto à "autonomia do político", voltando ao Partido Comunista Italiano. Ver, também, Gentili (2013). Para uma visão mais geral da época, por outra vertente de esquerda do PCI, ver Magri (2009).

4 Partindo de visão contrária a esse entendimento da teoria do valor, Offe (I973) sublinhou as contradições e conflitos que surgiam em função da tendência à ampliação de formas de trabalho que não se baseavam na forma mercadoria e no salário, senão na produção de valor de uso e na 
"renda", basicamente na segunda fase da modernidade, calcada no fortalecimento do Estado. O neoliberalismo e a "acumulação por despossessão" vieram, sob a ótica do capital, atacar em larga medida esse tipo de problema. Outra referência fundamental no debate sobre a teoria do valor é a obra de André Gorz, que não posso discutir aqui. Ver, porém, Silva (2007).

5 Nesse sentido é positivo que Honneth se disponha a renovar a ideia de socialismo, em parte tentando corrigir o caráter apologético da modernidade como liberdade já realizada tal qual presente em seu livro anterior. Mas, além de não chegar sequer a problematizar o poder dos grandes aparelhos econômicos e políticos modernos, a rigor descarta a luta e mobilização de massas, bem como simplesmente assimila, sem maiores elaborações e sem mostrar qual de fato a relação entre diversas demandas, a questão das tendências de desenvolvimento na direção ao socialismo à necessidade de inclusão de qualquer grupo excluído acentuando a dimensão moral, transnacional hoje, a ser trabalhada na esfera pública (Honneth, 20I5: I62). As esferas hegelianas diferenciadas da política, da economia e da família não se alterariam ademais pelo experimentalismo socialista que propugna, o que nos deixa trancafiados na modernidade.

\section{REFERÊNCIAS BIBLIOGRÁFICAS}

Aricó, José. (2012) [I976-I977]. Nueve lecciones sobre economía y política en el marxismo. México: Fondo de Cultura Económica e El Colegio de México.

Bellofiore, Ricardo; Starosta, Guido \& Thomas, Peter D. (orgs.). (20I3). In Marx's Laboratory: critical interpretations of the Grundrisse. Leiden: Brill.

Bernstein, Eduard. (I997) [I899]. Socialismo evolucionário. Rio de Janeiro: Zahar.

Cohen, Jean \& Arato, Andrew. (I992). Civil society and political theory. Cambridge, MA: MIT Press.

Domingues, José Maurício. (2014). Global modernity, levels of analysis and conceptual strategies. Social Science Information, 53, p. I80-96. 
Domingues, José Maurício. (2013). Imaginário e política na modernidade. A trajetória do peronismo. Cadernos de Trabalho, 2 (Netsal/IESP-UERJ).

Domingues, José Maurício. (2013) [2012]. Modernidade global e civilização contemporânea. Para a renovação da teoria crítica. Belo Horizonte: Ed. UFMG.

Domingues, José Maurício. (2002). Interpretando a modernidade. Imaginário e instituições. Rio de Janeiro: Ed. FGV.

Domingues, José Maurício. (I999). Criatividade social, subjetividade coletiva e a modernidade brasileira contemporânea. Rio de Janeiro: Contra Capa.

Elster, Jon. (1985). Making sense of Marx. Cambridge: Cambridge University Press.

Gentili, Dario. (2013). Una crisi italiana. Alla radice della teoría dell'autonomia del político. Il Rasoio di Occam, 27 de fevereiro. Disponível em: <http://ilrasoiodioccam-micromega.blogautore.espresso.repubblica.it/2013/02/27/una-crisi-italiana-alla-radice-della-teoria-dellautonomia-del-politico/?refresh_ce>. Acesso em 25 jan. 2016.

Grossmann, Henryk. (1967) [1929]. Das Akkumulation - und Zusammenbruchgesetz des kapitalistischen Systems. Frankfurt am Main: Neue Kritik.

Habermas, Jürgen. (20I 2) [I98I]. Teoria do agir comunicativo. São Paulo: Martins Fontes, (vols. I-2).

Habermas, Jürgen. (I 997) [I992]. Direito e democracia. Entre faticidade e validade. Rio de Janeiro: Tempo Brasileiro.

Habermas, Jürgen. (I983) [1976]. Para a reconstrução do materialismo histórico. São Paulo: Brasiliense.

Hardt, Michael \& Negri, Antonio. (20II). Commonwealth. Cambridge, MA: Harvard University Press.

Hardt, Michael \& Negri, Antonio. (2005) [2004]. Multidão. Guerra e democracia na era do Império. Rio de Janeiro: Record. Hardt, Michael \& Negri, Antonio. (2004) [1994]. Trabalho de Dionísio. Para a crítica ao Estado pós-moderno. Rio de Janeiro/ Juiz de Fora: Pazulin/Ed. UFJF.

Hardt, Michael \& Negri, Antonio. (200I) [2000]. Império. Rio de Janeiro: Record.

Harvey, David. (20I4). Seventeen contradictions and the end of capitalism. Nova York: Oxford University Press. 
Harvey, David. (20 I I) [2009]. O enigma do capital e as crises do capitalismo. São Paulo: Boitempo.

Harvey, David. (2004) [2003]. O novo imperialismo. São Paulo: Loyola.

Heinrich, Michael. (2013). Crisis theory, the law of the tendency of the profit rate to fall, and Marx's studies in the I970s. Monthly Review, 64/I I. Disponível em <http://monthlyreview.org/2013/04/or/crisis-theory-the-law-of-the-tendency-of-the-profit-rate-to-fall-and-marxs-studies-in-the-1870s/>. Acesso em 3 mar. 2016.

Heinrich, Michael. (2003). Die Wissenschaft vom Wert. Die Marxsche Kritik der politischen Ökonomie zwischen wissenshaftlicher Revolution und klassischer Tradition. Münster: Westfälisches Dampfboot.

Honneth, Axel. (2015). Die Idee des Sozialismus. Frankfurt am Main: Suhrkamp.

Kalyvas, Andreas. (2005). Democracy and the politics of the extraordinary: Max Weber, Carl Schmitt, and Hannah Arendt. Cambridge: Cambridge University Press.

Kautsky, Karl. (I979) [I 909]. O caminho do poder. São Paulo: Hucitec.

Laclau, Ernesto. (2013) [2005]. A razão populista. São Paulo: Três Estrelas.

Laclau, Ernesto \& Mouffe, Chantall. (I989). Hegemony and socialist strategy: towards a radical democratic politics. Londres / Nova York: Verso.

Lênin, Vladimir. (I986) [I9I7]. Imperialismo, fase superior do capitalismo (ensaio popular). São Paulo: Alfa-Ômega.

Luxemburg, Rosa. (I983) [I9I3]. A acumulação do capital. Rio de Janeiro: Zahar.

Magri, Lucio. (2013) [2009]. O alfaiate de Ulm. Uma possível história do Partido Comunista Italiano. São Paulo: Boitempo. Marx, Karl. (s/d.) [I845]. Teses sobre Feuerbach. In: Marx, Karl \& Engels, Friedrich. Obras escolhidas. São Paulo: Alfa-Ômega (vol. I.).

Marx, Karl. (201 I) [I857-I 858]. Grundrisse. Manuscritos Econômicos de I857-58. São Paulo: Boitempo.

Marx, Karl. (I980) [I867]. O capital (Livro I). Rio de Janeiro: Civilização Brasileira. 
Marx, Karl. (s/d.) [187I]. A guerra civil na França. In: Marx, Karl \& Engels, Friedrich. Obras escolhidas. São Paulo: Alfa-Ômega (vol. 2).

Marx, Karl. (s/d) [1875]. Crítica ao Programa de Gotha. In: Marx, Karl \& Engels, Friedrich. Obras escolhidas. São Paulo: Alfa-Ômega (vol. 3).

Marx, Karl. (I980) [1883]. O capital (Livro II). Rio de Janeiro: Civilização Brasileira.

Marx, Karl. (I980) [I894]. O capital (Livro III). Rio de Janeiro: Civilização Brasileira.

Marx, Karl \& Engels, Friedrich. (s/d) [I848]. Manifesto do Partido Comunista. In: Marx, Karl \& Engels, Friedrich. Obras escolhidas. São Paulo: Alfa-Ômega (vol. I).

Marx, Karl \& Engels, Friedrich. (2007) [I845]. A ideologia alemã. São Paulo: Boitempo.

Michels, Robert. (I982) [I9I5]. Sociologia dos partidos políticos. Brasília: Ed. UnB.

Murphy, Timothy S. (20I 2). Antonio Negri. Cambridge: Polity. Negri, Antonio. (2005). The politics of subversion: a manifesto for the twenty-first century. (2. ed.). Cambridge: Polity.

Negri, Antonio. (2003) [1979]. Marx oltre Marx. Quaderno di lavoro sui Grundrisse. Roma: Manifestolibri.

Negri, Antonio. (2002) [I992]. O poder constituinte. Ensaio sobre as alternativas da modernidade. Rio de Janeiro: DP\&A. Negri, Antonio. (1998). Reviewing the experience of Italy in the I970s. Le Monde Diplomatique, English edition, setembro. Offe, Claus. (I 984) [I 973]. Problemas estruturais do Estado capitalista. Rio de Janeiro: Tempo Brasileiro.

Santos, Boaventura de Sousa. (2010). Refundación del Estado en América Latina. Perspectivas desde una epistemología del Sur. Lima: Instituto Internacional de Derecho y Sociedad. Santos, Boaventura de Sousa. (2007). Renovar a teoria crítica e reinventar a emancipação social. São Paulo: Boitempo.

Santos, Boaventura de Sousa. (2000). A crítica da razão indolente. Contra o desperdício da experiência. São Paulo: Cortez. Santos, Boaventura de Sousa. (I999). "Por que é tão difícil construir uma teoria crítica?". Revista Crítica de Ciências Sociais, 54, p.197-2I5. 
Santos, Boaventura de Sousa. (I995). Pela mão de Alice. O social e o político na pós-modernidade. São Paulo: Cortez.

Sartre, Jean-Paul. (2002) [I960]. Crítica da razão dialética. Rio de Janeiro: DP\&A.

Silva, Josué Pereira da. (2007). André Gorz: trabalho e política. São Paulo: Annablume.

Sweezy, Paul. (I983) [1946]. Teoria do desenvolvimento capitalista. Princípios de economia marxista. São Paulo: Abril.

Therborn, Göran. (2012) [2008]. Do marxismo ao pós-marxismo? São Paulo: Boitempo. 


\section{TEORIA SOCIAL CRÍTICA E TENDÊNCIAS DE DESENVOLVIMENTO, EMANCIPAÇÃO E COMUNISMO TARDIO \\ Resumo}

Este texto explora duas propostas de teorização da mudança social contemporânea e as tendências que discernem como abrigadas no desenvolvimento social na direção da emancipação, nos quadros de uma renovada teoria crítica. Inicialmente discutem-se as versões marxistas desses processos e em seguida as obras de Antonio Negri e Boaventura de Sousa Santos. Apesar de sua complexidade, em ambas se identificam falhas e equívocos a serem superados. Recusa-se o imediatismo da "multidão" e a reificação da diferença. Argumenta-se então que segue sendo necessário identificar as tendências de desenvolvimento da modernidade, com destaque para o sistema político, seus pontos de tensão e possível modificação, com por outro lado uma atitude mais modesta e prudente face à identificação da totalidade e estratégias que se supõem derivar disso de forma direta e absoluta.

\section{CRITICAL SOCIAL THEORY AND DEVELOPMENTAL TRENDS, EMANCIPATION AND LATE COMMUNISM}

Abstract

This text explores two proposals of theorization of contemporary social change and the tendencies they devise as harboured in social development in an emancipatory direction within the framework of a renewed critical theory. Marxist views of such processes are initially discussed, followed by that of Antonio Negri's and Boaventura de Sousa Santos' works. Despite their complexity, flaws and mistakes are found in them both, which must be overcome. The immediacy of the 'multitude' and the reification of difference are rejected. It argues then that it remains necessary to identify the developmental tendencies of modernity, especially of its political system, with its fault lines and possible alteration, with on the other hand a more modest and prudent attitude towards the identification of totality and the strategies supposed to be directly and absolutely derivable from it.
Palavras-chave

Tendências de desenvolvimento; Comunismo; Marxismo;

Negri;

Sousa Santos.

\section{Keywords}

Developmental trends;

Communism;

Marxism;

Negri;

Sousa Santos. 